\title{
Antibiogram of Pathogenic Urinary E.coli Isolates from Tertiary Care Hospital in Kerala, India
}

\author{
Riyaz Sheriff*, K.K. Prasobh, N. Simi and A. Neena \\ Department of Microbiology, Azeezia Institute of Medical Sciences \& Research, \\ Kollam, Kerala, India \\ *Corresponding author
}

\section{Keywords}

Urinary E.coli, Antibiotic resistance, E.coli, Urinary tract infection, Antibiotic sensitivity profile

Article Info

Accepted:

22 July 2018

Available Online:

10 August 2018

\section{A B S T R A C T}

Urinary tract infections are one of the most common causes of patient attendance in hospitals. E.coli remains the most commonly isolated pathogen causing Urinary tract infections. Antibiotic resistance is an emerging problem in developing countries. The way ahead is to streamline the utilisation of antibiotics and to implement locally relevant antibiotic policy. A total of 1152 urine samples were received during the study period. 327 samples grew monobacterial significant bacteriuria. Semi-quantitative cultures were performed. The isolates were tested for sensitivity to the following discs Ampicillin $(10 \mu \mathrm{g})$, Gentamicin $(10 \mu \mathrm{g})$, Tobramycin $(10 \mu \mathrm{g})$, Amikacin $(30 \mu \mathrm{g})$, Ciprofloxacin $(5 \mu \mathrm{g})$ Levofloxacin $(5 \mu \mathrm{g})$, Cotrimoxazole $(1.25 / 23.75 \mu \mathrm{g})$ Amox-Clavulanic Acid $(20 / 10 \mu \mathrm{g})$ Piperacillin-Tazobactum $(100 / 10 \mu \mathrm{g})$ Norfloxacin $(10 \mu \mathrm{g})$ Amikacin $(30 \mu \mathrm{g})$ Cefuroxime $(30 \mu \mathrm{g})$, Ceftriaxone $(30 \mu \mathrm{g})$, Ceftazidime $(30 \mu \mathrm{g})$, Ceftazidime- Clavulanic Acid $(30 / 10 \mu \mathrm{g})$, Cefotaxime $(30 \mu \mathrm{g})$ Imipenam $(10 \mu \mathrm{g})$, Tetracycline $(30 \mu \mathrm{g})$, Nitrofurantoin $(300 \mu \mathrm{g})$. The sensitivity was recorded and reported as per the CLSI 2017 guidelines. Antibiotic sensitivity profile of E.coli shows sensitivity to Imipenam (91\%), Nitrofurantoin (97\%), Amikacin (91\%), Tobramycin (72\%), Piperacillin-Tazobactum (77\%), Gentamicin (66\%) and Tetracycline (46\%). E.coli isolated exhibited resistance to ampicillin, amoxicillinclavulanic acid, $2^{\text {nd }}$ and $3^{\text {rd }}$ generation cephalosporins and fluroquinolones. E.coli was sensitive to cotrimoxazole in $49 \%$ isolates. $62(48.1 \%)$ isolates were resistant to 3 or more antibiotic groups (MDR). 17 of the 148 isolates exhibited Extended drug resistant (XDR) E.coli showed high degree of resistance to cephalosporins and fluroquinolones. One of the short term measures advised is antibiotic cycling to prolong the usefulness of live saving drugs. For this every healthcare unit needs to develop their own antibiogram to have a clear picture of the antibiotic resistance pattern prevalent in the area.

\section{Introduction}

Urinary tract infections (UTI) are the most common cause of patients attending hospital. Uncomplicated symptomatic UTI presenting with dysuria, fever and lower abdominal pain especially in female patients is a common scenario in India. Urine sample remains the most frequent sample submitted to Microbiology laboratory for identification of offending pathogen. The main cause of urinary tract infection in India remains to be the members of Enterobacteriaceae family. This is followed by members of Pseudomonas 
family, Staphylococcus aureus and Enterococcus sp. Among the members of Enterobacteriaceae Escherichia coli remains the most important pathogen causing uncomplicated UTI. E. coli infections are more common in women which may be attributed to the anatomical proximity to the gastrointestinal tract which harbours E.coli as a commensal (Richard Colgan and Mozella Williams, 2011; Mohammed Akram et al., 2007). Klebsiella pneumoniae is the next most commonly isolated gram negative bacteria from Enterobacteriaceae family. Few infections are caused by Klebsiella oxytoca, Proteus mirabilis, Proteus vulgaris and Citrobacter sp. Among the gram positive bacteria Staphylococcus aureus and Enterococcus are responsible for few uncomplicated UTI's. Coagulase Negative Staphylococci (CoNS) remain a gray area in microbiological diagnosis of UTI. Being the part of skin commensals CoNS are not generally reported as an offending organism. In the recent years there have been reports of CoNS causing clinically relevant infections. CoNS infections are more common in immunocompromised population but there have been reported studies on capability of CoNS in causing infections in immunocompetent people as well. Members like Staphylococcus hemolyticus, Staphylococcus lugdunensis and Staphylococcus saprophyticus are notorious in causing human infections. The role Pseudomonas aeruginosa in causing UTI is well known. Being a hardy organism capable of growing on varied substrates including disinfectants are seen pan environmentally the isolation of Pseudomonas aeruginosa needs correlation with clinical condition of the patient. Nevertheless the role of Pseudomonas aeruginosa in causing UTI cannot be underplayed.

Antibiotic resistance has been emerging in India (Muktikesh Dash et al., 2013). It has reached a stage of being one of the most important public health problems which needs to be tackled. Since the reason for spreading antimicrobial resistance is multi-factorial, there needs to be coordination and exchange of information among all those involved in healthcare. Resistant isolates are seen both in Enterobacteriaceae as well as in gram positive bacteria. The most commonly isolated bacteria are E.coli and Klebsiella. Among E.coli the resistance to commonly used antibiotics is on the rise. A study conducted in 2014 reports a high degree of resistance to Ampicillin (88.4\%) followed by Amoxicillin-clavulanic acid (74.4\%), Norfloxacin (74.2\%), Cefuroxime (72.2\%), Ceftriaxone (71.4\%) and Cotrimoxazole (64.2\%) (Niranjan and Malini, 2014). The antibiotic susceptibility data for uropathogens in India is very minimal. There have been very few community or hospital based studies to assess the problem burden. Our literature search revealed wide variations in the resistance pattern of E.coli. The present study was undertaken to assess the antimicrobial susceptibility patterns of E.coli in order to guide the clinician regarding presumptive antibiotic usage in UTI patients. There exists lacunae with regard to quantification of the problem and various determining factors related to antimicrobial resistance. There is an urgent need to develop and strengthen antimicrobial policy, standard treatment guidelines, national plan for containment of AMR and research related to public health aspects of AMR at community and hospital level in India (Ganesh Kumar et al., 2013)

\section{Materials and Methods}

Freshly void mid-stream urine samples received in the Microbiology laboratory of Azeezia Institute of Medical Sciences and Research from January 2017 to December 2017 were included in the study. A total of 1152 urine samples were received during the study period. 327 samples grew monobacterial 
significant bacteruria. 611 samples did not show any growth and 173 samples grew more than 3 types of colonies and were hence termed as mixed growth. The samples were initially examined by wet mount. Semiquantitative cultures were performed using calibrated loop method on 5\% Sheep blood agar and Mac Conkey agar. The plates were incubated at $37^{\circ} \mathrm{C}$ for $18-24$ hours. Significance of samples was determined as per Kass criteria (European Association of Urology, 2013). Samples growing single bacterial species with $>10^{5} \mathrm{cfu} / \mathrm{ml}$ were considered as significant bacteruria samples. Isolates were identified based on the colony morphology, Gram staining and standard biochemical reactions (Koneman et al., 2006; Gerald Collee et al., 14 ${ }^{\text {th }}$ edn). The isolates were then subjected to Antibiotic sensitivity testing as per Clinical and Laboratory Standards Institute (CLSI) 2017 guidelines (Performance Standards for Antimicrobial Susceptibility Testing). The Antibiotic sensitivity testing was done on Meuller Hinton agar. Standard strain American Type Culture Collection (ATCC) strain of E.coli 25922 was used as a control. The culture media were obtained from Himedia labs, Mumbai, India and were prepared in-house. The prepared plates were approved for use after internal quality control. The antibiotic discs were obtained from Himedia labs as well. The isolates were tested for sensitivity to the following discs Ampicillin $(10 \mu \mathrm{g})$, Gentamicin $(10 \mu \mathrm{g})$, Tobramycin $(10 \mu \mathrm{g})$, Amikacin (30 $\mu \mathrm{g}), \quad$ Ciprofloxacin $\quad(5 \mu \mathrm{g})$ Levofloxacin $\quad(5 \mu \mathrm{g}) \quad$ Cotrimoxazole $(1.25 / 23.75 \mu \mathrm{g}) \quad$ Amox-Clavulanic Acid $(20 / 10 \mu g) \quad$ Piperacillin-Tazobactum $(100 / 10 \mu \mathrm{g})$ Norfloxacin $(10 \mu \mathrm{g})$ Amikacin $(30 \mu \mathrm{g}) \quad$ Cefuroxime $(30 \mu \mathrm{g})$, Ceftriaxone $(30 \mu \mathrm{g})$, Ceftazidime $(30 \mu \mathrm{g})$, CeftazidimeClavulanic Acid (30/10 $\mu \mathrm{g})$, Cefotaxime $(30 \mu \mathrm{g})$ Imipenam $(10 \mu \mathrm{g})$, Tetracycline $(30 \mu \mathrm{g})$, Nitrofurantoin $(300 \mu \mathrm{g})$. The sensitivity was recorded and reported as per the CLSI 2017 guidelines.

\section{Results and Discussion}

Among the 1152 urine samples received for culture and sensitivity 327 samples (28.4\%) were identified as significant bacteruria samples. $611(53.03 \%)$ samples did not show any growth after 24 hours of incubation. These samples were further incubated for 24 hours and declared as culture negative at the end of 48hours. $173(15.01 \%)$ samples grew more than 3types of colonies after 24hours of incubation. These samples were reported as mixed growth along with comment to repeat sample with Clean Catch Mid-Stream urine (CCMSU). The predominant growth was E.coli (148 isolates - 45.29\%). $22.67 \%$ isolated were identified as Klebsiella pneumoniae. Gram positive bacteruria comprising of Enterococcus sp, Staphylococcus $\mathrm{sp}$ and Streptococcus $\mathrm{sp}$ constituted $15.90 \% \quad$ (52 isolates). The percentage distribution is provided in Table 1. Gender wise, more E.coli were isolated from female patients. Among the 148 isolates of E.coli in significant bacteruria samples 96 isolates were from female patients and 52 isolates from male patients (Table 2). The proportions of mixed growths were also higher among samples received from female patients. 141 samples out of the total 1152 showed mixed growths in females $(12.23 \%)$ whereas in males 33 samples were reported as mixed growth $(2.86 \%)$. Most of the E.coli isolates were isolated from in-patients in our study (89 isolates). 31 and 28 isolates were obtained from samples received from out patients and Intensive care units respectively (Table 3 ). Out of 148 isolates of E.coli 96 were obtained from female patients. 69 out of these isolates were from female patients admitted in the hospital. The majority of E.coli was isolated from samples received from General medicine department $(50.7 \%)$. The rest were isolated from samples received from Emergency, Obstetrics and Gynaecology, General Surgery, 
Urology, paediatrics and Orthopaedics department (Table 4). In our study the Urinary Tract Infections due to E.coli are more common in females from the second decade of life. In males the infection due to E.coli was more common after $5^{\text {th }}$ decade (Table 5).

First isolates of each patient were considered for the antibiogram. 129 first time isolate analysis showed sensitivity to Imipenam (91\%), Nitrofurantoin (97\%), Amikacin (91\%), Tobramycin (72\%), PiperacillinTazobactum (77\%), Gentamicin (66\%) and Tetracycline $(46 \%)$. E.coli isolated exhibited resistance to Ampicillin, AmoxicillinClavulanic acid, $2^{\text {nd }}$ and $3^{\text {rd }}$ generation Cephalosporins and Fluroquinolones. E.coli was sensitive to Cotrimoxazole in $49 \%$ isolates

The antibiotic sensitivity pattern was assessed for Multi Drug Resistant Organisms (MDRO). Of the 129 first time E.coli isolates 50 were sensitive to most drugs (38.7\%), 62 isolates were resistant to at least one antibiotic in three or more groups (48.1\%) 17 strains of E.coli exhibited resistance to most antibiotics barring two or less groups $(13.2 \%)$ and were termed as XDR isolates (Koneman et al., 2006). We did not come across any Pan drug resistant strains in this study (Silpi Basak et al., 2016).

Around 150 million UTIs occur yearly on a global basis; resulting in more than 6 billion dollars in direct health care expenditures Infections are rare in boys except in association with anatomic or functional abnormalities in the first year of life.

Infections are also infrequent among 2- to 13year-old girls, but some young girls experience multiple repeated episodes of recurrent cystitis or pyelonephritis. The incidence of UTIs markedly increases among young women during adolescence. As per the study carried out by Prinja et al., Rs.1713 is spent per head towards healthcare expenditure annually (Prinja et al., 2012).

\section{Table.1 Distribution of isolates in the urine samples ( $N=1152)$}

\begin{tabular}{|l|l|l|}
\hline Isolates & Number $\mathbf{( N = 3 6 6 )}$ & Percentage (\%) \\
\hline E.coli & 148 & 40.44 \\
\hline Klebsiella pneumoniae & 74 & 20.22 \\
\hline Enterococcus sp & 27 & 7.38 \\
\hline Staphylococcus aureus & 16 & 4.37 \\
\hline Pseudomonas aeruginosa & 15 & 4.10 \\
\hline Coagulase Negative Staphylococcus aureus & 3 & 0.82 \\
\hline Enterobacter aerogenes & 14 & 3.83 \\
\hline Acinetobacter sp & 10 & 2.73 \\
\hline Streptococcus sp & 6 & 1.64 \\
\hline Proteus sp & 8 & 2.19 \\
\hline Citrobacter sp & 6 & 1.64 \\
\hline Candida albicans & 12 & 3.28 \\
\hline Candida non albicans & 27 & 7.38 \\
\hline Total number of reportable growth & 366 & 100.00 \\
\hline Non reportable growths & & \\
\hline No growth & 612 & 53.1 \\
\hline Mixed growth & 174 & 15.1 \\
\hline
\end{tabular}




\section{Table.2 Gender Distribution of isolates in the urine samples ( $N=1152)$}

\begin{tabular}{|l|c|c|c|}
\hline Isolates & Number (N=366) & Males & Females \\
\hline E.coli & 148 & 52 & 96 \\
\hline Klebsiella pneumoniae & 74 & 36 & 38 \\
\hline Enterococcus sp & 27 & 12 & 15 \\
\hline Staphylococcus aureus & 16 & 2 & 4 \\
\hline Pseudomonas sp & 15 & 11 & 3 \\
\hline CoNS & 3 & 0 & 4 \\
\hline Enterobacter sp & 14 & 10 & 4 \\
\hline Acinetobacter sp & 10 & 6 & 4 \\
\hline Streptococcus sp & 6 & 2 & 2 \\
\hline Proteus sp & 8 & 6 & 4 \\
\hline Citrobacter sp & 6 & 2 & 3 \\
\hline Candida alloicans & 12 & 9 & 6 \\
\hline Candida non albicans & 27 & 21 & 197 \\
\hline Total number of & 366 & 169 & \\
\hline reportable growth & & & \\
\hline Non reportable growth & & & 394 \\
\hline No growth & 612 & 218 & 141 \\
\hline Mixed growth & 174 & 33 & \\
\hline
\end{tabular}

\section{Table.3 Location wise Distribution of E.coli isolates}

\begin{tabular}{|l|}
\hline Location type \\
\hline Inpatients $(\mathrm{N}=\mathbf{8 9})$ \\
\hline Intensive care $(\mathrm{N}=\mathbf{2 8})$ \\
\hline Outpatients $(\mathrm{N}=\mathbf{3 1})$ \\
\hline Total $(\mathbf{N}=\mathbf{1 4 8})$
\end{tabular}

Female

54

15

27

\section{Male \\ 35 \\ 13 \\ 4}

Table.4 Department wise distribution of E.coli isolates

\begin{tabular}{|l|}
\hline Department \\
\hline General medicine \\
\hline Emergency \\
\hline Obstetrics and Gynaecology \\
\hline Urology \\
\hline General surgery \\
\hline Orthopaedics \\
\hline Paediatrics \\
\hline Neurology \\
\hline Cardiology \\
\hline Pulmonology \\
\hline Nephrology \\
\hline
\end{tabular}

\begin{tabular}{|c|c|}
\hline Number & Percentage $(\%)$ \\
\hline 75 & 50.7 \\
\hline 16 & 10.8 \\
\hline 15 & 10.1 \\
\hline 13 & 8.8 \\
\hline 11 & 7.4 \\
\hline 8 & 5.4 \\
\hline 2 & 2.7 \\
\hline 2 & 1.4 \\
\hline 1 & 1.4 \\
\hline 1 & 0.7 \\
\hline
\end{tabular}




\begin{tabular}{|l|c|c|c|c|}
\hline \multicolumn{4}{|c|}{ Table.5 Age-wise distribution of E.coli isolates (N=148) } \\
\hline Age category & Males & Number & \multicolumn{2}{c|}{ Percentage } \\
\hline <1 & 1 & 0 & Males & Females \\
\hline 1-10years & 2 & 3 & 0.68 & 0.00 \\
\hline 11-20Years & 0 & 2 & 1.35 & 2.03 \\
\hline 21-30years & 0 & 14 & 0.00 & 1.35 \\
\hline 31-40years & 0 & 12 & 0.00 & 9.46 \\
\hline 41-50years & 1 & 11 & 0.60 & 8.11 \\
\hline 51-60years & 13 & 14 & 8.78 & 7.43 \\
\hline 61-70years & 11 & 16 & 7.43 & 9.46 \\
\hline 71-80years & 13 & 15 & 8.78 & 10.81 \\
\hline 81-90years & 10 & 9 & 6.76 & 6.14 \\
\hline >91years & 1 & 0 & 0.68 & 0.00 \\
\hline
\end{tabular}

This is bound to go up with drug resistant E.coli causing UTI. E.coli is the most common organism isolated from urinary tract infections in India as well (Atul Kothari and Vishal Sagar, 2008). The rate of culture positivity is quite low in most of the studies. In our study 611 samples out of the 1152 samples received did not grow any bacteria. The possible explanation for this can be incorrect timing of the sample collection or sample may have been taken after administration of antibiotic. In the current scenario of over the counter medications most patients tend to start antibiotics even before they report to health care facility. 169 samples were reported as mixed growth. This could be minimized by giving proper instructions are given to the patients regarding sample collection (CCMSU). Secondly in our study most mixed growth samples were seen in females which may be due to anatomical proximity of gastrointestinal tract to genitourinary tract in females. Nevertheless proper instructions on Ano-genital toilet and proper timing of sample collection can bring down the proportion of non-reportable culture growths.

Among the samples showing significant monobacterial growth E.coli was predominant. Age wise split showed that the Urinary tract infections in female patients were more common from $2^{\text {nd }}$ to $5^{\text {th }}$ decade of life. In males the incidence of urinary tract infections due to E.coli was more predominant after $5^{\text {th }}$ decade of life (Devanand Prakash and Ramchandra Sahai Saxena, 2013).

In our study E.coli showed high degree of resistance to Cephalosporins and Fluroquinolones. This correlates with the prescribing trends prevailing in this part of the country. Now the million dollar question is how to avoid resistance. There have been many suggestions, recommendations from international agencies (WHO and CDC). They recommended strict control on antibiotic use by humans. A prescription should be mandatory for procuring the antibiotic. Secondly the international agencies have also called for controlled therapeutic use of antibiotics in animal husbandry. The next method suggested in antibiotic cycling. For this every healthcare unit needs to develop their own antibiogram to have a clear picture of the antibiotic resistance pattern prevalent in the area. Antibiotic cycling is a short term measure to tackle antibiotic resistance and also to prolong the usefulness of live saving 
drugs. This procedure will reduce the selection pressure for resistance (Silpi Basak et al., 2016).

The Chennai declaration documented the fact of emergence of antibiotic resistance in India and it aimed to form a "Road map" to tackle the menace of antibiotic resistance in India using a stepwise approach (Ghafur et al., 2012). The uniform consensus was that there is paucity of published data and antibiotic usage and antibiotic resistance in India. The road map included regulation of over the counter sale of antibiotics, in-hospital antibiotic usage monitoring and stringent supervision on usage of life-saving drugs. It was also decided that ICMR would set up a National antibiotic resistance surveillance system with representations from all parts of the country (Magiorakos et al., 2012). The ICMR has come out with Treatment guidelines for antimicrobial use in common syndromes -2017 . These were based on data obtained from central institutes (PGIMER, AIIMS, JIPMER, and CMC Vellore) and available national data. These guidelines show high degree of resistance to Cefotaxime (72-87\%), Ceftazidime (72-89\%) and Ciprofloxacin (74-90\%). As per the recommendation issued by ICMR Nitrofurantoin, Cotrimoxazole and Ciprofloxacin have been suggested as first line drugs for acute uncomplicated cystitis in the absence of cultures. In our Study E.coli were sensitive to Nitrofurantoin. There was high degree of resistance to Cotrimoxazole $(55 \%)$ and Ciprofloxacin (63\%). The effectiveness of these drugs in treatment of cystitis will have to be relooked and assessed based on the national level data from surveillance network.

\section{References}

Atul Kothari and Vishal Sagar. Antibiotic resistance in pathogens causing community-acquired urinary tract infections in India: a multicenter study. J Infect Developing Countries 2008; 2(5): 354-358.

Devanand Prakash and Ramchandra Sahai Saxena. Distribution and Antimicrobial Susceptibility Pattern of Bacterial Pathogens Causing Urinary Tract Infection in Urban Community of Meerut City, India. ISRN Microbiology Volume 2013, Article ID 749629.

European Association of Urology. Guidelines on Urological infections. Urological infection 2013. Pg. 1-108

Ganesh Kumar, Adithan, Harish, Sujatha, Gautam Roy and Malini. Antimicrobial resistance in India: A review. Journal of Natural Science, Biology and Medicine. July 2013. Vol 4. Issue 2. pg 286-291

Gerald Collee, Miles and Watt. Tests for identification of Bacteria. Mackie and McCartney Practical Medical Microbiology. $14^{\text {th }}$ edition. Pp. 113-150

Ghafur A, Mathai D, Muruganathan A, Jayalal JA, Kant R, Chaudhary D and et al., Recommendations of "A roadmapto tackle the challenge of antimicrobial resistance" - A joint meeting of medical societies of India. Indian Journal of Cancer 2012; 49(4): 71-81.

Koneman E.W, Allen S.D, Janda W M, Schreckenberger PC. Colour Atlas of Diagnostic Microbiology $7^{\text {th }}$ edition San Francisco Lippin Cott., 2006 Pp. 471646.

Magiorakos, A. Srinivasan, R. B. Carey, Y. Carmeli, M. E. Falagas, C. G. Giske and et al., Multidrug-resistant, extensively drug-resistant and pandrug-resistant bacteria: an international expert proposal for interim standard definitions for acquired resistance. Clin Microbiol Infect 2012; 18: 268-281

Mohammed Akram, Mohammed Shahid and Asad U Khan. Etiology and antibiotic resistance patterns of community- 
acquired urinary tract infections in $\mathrm{J} \mathrm{N}$ M C Hospital Aligarh, India. Annals of Clinical Microbiology and Antimicrobials 2007, 6:4

Muktikesh Dash, Sanghamitra Padhi, Indrani Mohanty, Pritilata Panda, Banojini Parida. Antimicrobial resistance in pathogens causing urinary tract infections in a rural community of Odisha, India. Journal of Family and Community Medicine; 2013; 20(1): 2026.

Niranjan V, and Malini A. Antimicrobial resistance pattern in Escherichia coli causing urinary tract infection among inpatients. Indian J Med Res 139, June 2014, pp. 945-948.

Performance Standards for Antimicrobial Susceptibility Testing. 27th edition.
Clinical and Laboratory Standards Institute. Pp. 62-73.

Prinja S, Bahuguna P, Pinto AD, Sharma A, Bharaj G, et al., (2012) The Cost of Universal Health Care in India: A Model Based Estimate. PLoS ONE 7(1):e30362.

doi:10.1371/journal.pone.0030362

Richard Colgan and Mozella Williams. Diagnosis and Treatment of Acute Uncomplicated Cystitis. American family physician. 2011. Available from www.aafp.org/afp. accesses on September 142017.

Silpi Basak, Priyanka Singh, and Monali Rajurkar. Multidrug Resistant and Extensively Drug Resistant Bacteria: A Study. Journal of Pathogens Volume 2016, Article ID 4065603

\section{How to cite this article:}

Riyaz Sheriff, K.K. Prasobh, N. Simi and Neena, A. 2018. Antibiogram of Pathogenic Urinary E.coli Isolates from Tertiary Care Hospital in Kerala, India. Int.J.Curr.Microbiol.App.Sci. 7(08): 4190-4197. doi: https://doi.org/10.20546/ijcmas.2018.708.438 